\title{
Projections of climate conditions that increase coral disease susceptibility and pathogen abundance and virulence
}

Maynard, J.; van Hooidonk, R.; Eakin, C.M.; Puotinen, M.; Garren, M.; Williams, G.J.; Heron, S.F.; Lamb, J.; Weil, E.; Willis, B.; Hervell, C.D.

\section{Nature Climate Change}

DOI:

10.1038/nclimate2625

Published: 04/05/2015

Cyswllt i'r cyhoeddiad / Link to publication

Dyfyniad o'r fersiwn a gyhoeddwyd / Citation for published version (APA):

Maynard, J., van Hooidonk, R., Eakin, C. M., Puotinen, M., Garren, M., Williams, G. J., Heron, S. F., Lamb, J., Weil, E., Willis, B., \& Hervell, C. D. (2015). Projections of climate conditions that increase coral disease susceptibility and pathogen abundance and virulence. Nature Climate Change, 5, 688-694. https://doi.org/10.1038/nclimate2625

\footnotetext{
Hawliau Cyffredinol / General rights

Copyright and moral rights for the publications made accessible in the public portal are retained by the authors and/or other copyright owners and it is a condition of accessing publications that users recognise and abide by the legal requirements associated with these rights. study or research

- Users may download and print one copy of any publication from the public portal for the purpose of private

- You may not further distribute the material or use it for any profit-making activity or commercial gain

- You may freely distribute the URL identifying the publication in the public portal?
}

Take down policy

If you believe that this document breaches copyright please contact us providing details, and we will remove access to the work immediately and investigate your claim. 


\section{Climate projections of conditions that increase coral disease}

2 susceptibility and pathogen virulence

3

4

Running title: Climate projections of coral disease conditions

Jeffrey Maynard ${ }^{1,2^{*}}$, Ruben van Hooidonk ${ }^{3}$, C. Mark Eakin ${ }^{4}$, Marjetta Puotinen ${ }^{5}$, Melissa Garren $^{6}$, Gareth Williams ${ }^{7}$, Scott F. Heron ${ }^{4,8}$, Joleah Lamb ${ }^{1}$, Ernesto Weil ${ }^{9}$, Bette Willis ${ }^{10}$, C. Drew Harvell ${ }^{1}$

1 - Department of Ecology and Evolutionary Biology, Cornell University, Ithaca NY 14850, United States of America

2 - CRIOBE - USR 3278, CNRS - EPHE - UPVD, Laboratoire d'Excellence "CORAIL", 58 Av. Paul Alduy - 66860 Perpignan cedex, France 3 - NOAA Atlantic Oceanographic and Meteorological Laboratory 4301 Rickenbacker Causeway, Miami, FL 33149, USA and the Cooperative Institute for Marine and Atmospheric Studies, Rosenstiel School of Marine and Atmospheric Science, University of Miami, 4600 Rickenbacker Cswy., Miami, FL 33149, USA.

4-NOAA Coral Reef Watch, NESDIS Center for Satellite Applications and Research, 5830 University Research Ct., E/RA3, College Park, MD 20740, USA

5 - Australian Institute of Marine Science, 35 Stirling Hwy Crawley 6009, Western Australia, Australia 6 - Department of Civil and Environmental Engineering, Massachusetts Institute of Technology, 15 Vassar St., Cambridge, MA 02139 USA

7 - Center for Marine Biodiversity and Conservation, Scripps Institution of Oceanography, La Jolla California 92037, USA.

8 - Marine Geophysical Laboratory, Physics Department, College of Science, Technology and Engineering, James Cook University, Townsville, Queensland 4811, Australia

9 - Department of Marine Sciences, University of Puerto Rico, Mayaguez Puerto Rico, USA

10 - Australian Research Council (ARC) Centre of Excellence for Coral Reef Studies, and College of Marine and Environmental Sciences, James Cook University, Townsville, Queensland 4811, Australia

*E-mail: maynardmarine@gmail.com

Ph: +19106161096

Article type: Article

Keywords: anthropogenic stress, climate change, climate model, coral reefs, coral disease, IPCC, projections 
44 Rising sea temperatures are likely to increase the frequency of disease outbreaks

45 affecting reef-building corals through impacts on coral hosts and pathogens. We

46 present and compare climate model projections of temperature conditions that will

47 increase 1) coral susceptibility to disease, 2) pathogen abundance, and 3) pathogen

48 virulence. A moderate (RCP 4.5) and fossil fuel aggressive (RCP 8.5) emissions

49 scenario are examined. We also compare projections for the onset of disease-

50 conducive conditions and severe annual coral bleaching, and produce a disease risk

51 summary that combines climate and anthropogenic stress. There is great spatial

52 variation in the projections both among and within the major ocean basins in

53 conditions favouring disease development. Our results indicate disease is as likely to

54 cause coral mortality as bleaching in the coming decades. These projections identify

55 priority locations to reduce anthropogenic stress and test management interventions

56 to reduce disease impacts.

The 2014 boreal summer was the warmest on record ${ }^{1}$, breaking air temperature records

60 in hundreds of cities and causing unprecedented highs in sea surface temperatures in the

61 North Pacific ${ }^{2}$. Concurrently, a catastrophic outbreak of starfish wasting disease

62 decimated American west coast populations of $\sim 20$ starfish species ${ }^{3}$ and outbreaks of

63 eelgrass wasting disease resulted in declines in habitat area as high as $90 \%$ in parts of

64 California and Washington (Wyllie-Echeverria pers obs). Pathogens causing these

65 wasting disease outbreaks have been in the environment for at least decades ${ }^{4}$, although

66 the causative virus for seastar wasting is newly described ${ }^{3}$. These recent examples serve

67 as reminders that disease outbreaks can rapidly and extensively devastate populations of

68 keystone species and key habitat builders. Both events also caught the scientific and

69 management communities by surprise, underscoring the importance of developing

70 forecasts and long-term projections of conditions that increase outbreak likelihood.

72 Forecasts of conditions conducive to disease onset have been most extensively developed

73 for the agricultural crop sector ${ }^{5,6}$ because of the economic value of optimising the timing

74 of pesticide application. Studies presenting longer-term, climate-model-based projections 
75 of conditions that promote disease onset for other plants and animals are far more rare.

76 To date, climate models driven by Intergovernmental Panel on Climate Change (IPCC)

77 emissions scenarios have only been used to develop projections of conditions related to

78 the causative agents and vectors of human diseases ${ }^{7}$, such as malaria ${ }^{8-10}$ and

79 Chikungunya ${ }^{11}$. Overall, the science of developing forecasts and projections for wildlife

80 diseases is in its infancy and warrants much greater research focus ${ }^{7}$, especially in the

81 marine environment where disease outbreaks have been increasing in frequency and

82 severity over recent decades ${ }^{12}$.

84 Climate-related diseases have already severely impacted the primary framework builders

85 of coral reef habitats ${ }^{12-15}$. Of the range of bacterial, fungal, and protozoan diseases

86 known to affect stony corals ${ }^{16}$, many have explicit links to temperature, including black

87 band disease ${ }^{17}$, yellow band disease ${ }^{18,19}$, and white syndromes ${ }^{13,20,21}$. Here, we apply the

88 climate models used in the IPCC $5^{\text {th }}$ Assessment Report (see Table S1 for list) to project

89 three temperature conditions that increase the susceptibility of coral hosts to disease or

90 increase pathogen abundance or virulence.

92 We posit that temperature conditions that increase host susceptibility, pathogen

93 abundance and pathogen virulence will substantially increase the likelihood of disease

94 outbreaks once the set threshold frequencies and stress levels are surpassed. The output

95 from the climate model ensemble for each of these three conditions is a projected year by

96 which the target frequency or stress level is reached. All projections are presented for

97 RCP8.5, the emissions scenario that best characterises current conditions and emission 
98 trends, and for RCP4.5, which represents a pathway to stabilisation at $4.5 \mathrm{~W} / \mathrm{m}^{2}(\sim 650$

$99 \mathrm{ppm} \mathrm{CO}_{2}$ equivalent) after $2100^{22}$. Along with the individual projections, we present

100 maps of the earliest and latest projected year one of these three conditions favourable to

101 disease development is projected to occur. We also present: a) comparisons between the

102 projected timing of these conditions and annual severe coral bleaching, b) a map of a

103 composite metric of anthropogenic stressors that can also increase host susceptibility to

104 disease, and c) a map of disease risk under RCP8.5 that combines climate and

105 anthropogenic stress.

106

107 Projections of disease conditions

108 The year in which host susceptibility is projected to exceed the set threshold (i.e., sub-

109 lethal bleaching stress 3 times per decade) varied spatially throughout all reef regions, but

110 with a clear latitudinal trend. Reef locations in the tropics $\left(<23^{\circ}\right.$ latitude $)$ suffered thermal

111 stress conducive to disease before sub-tropical reefs $\left(23-32.5^{\circ}\right.$ latitude), a pattern that was

112 similar under both RCPs (Fig. 1a and Fig. 2a). There was little variation (<5 years) in the

113 projected timing of this condition among locations in the tropics (Fig. 1a). In contrast,

114 some northern hemisphere sub-tropical reefs, such as in the Red Sea and Persian Gulf,

115 were projected to experience these conditions $\sim 20$ years later than sub-tropical reefs in

116 the south of Australia and Madagascar. Overall, under both RCP8.5 and RCP4.5, the

117 median year this threshold will be surpassed was 2011 ; most ( 76\% as of 2014) of the

118 world's reefs are already experiencing thermal stress potentially conducive to disease

119 outbreaks. Under both RCP8.5 and 4.5, the metric for increased host-susceptibility will

120 be reached at $>90 \%$ of reef locations by 2020 (Fig. 2a). 
122 In contrast to patterns for the host susceptibility metric, there was no clear latitudinal

123 gradient in the projections for increased pathogen abundance (i.e., when cool season

124 temperatures have warmed by $\geq 0.5^{\circ} \mathrm{C}$ ) (Fig. $1 \mathrm{~b}$ ). Additionally, greater variation in the

125 projected timing of this condition among reefs within both the tropics and sub-tropics

126 was observed, as well as between the RCPs, than was seen for the host susceptibility

127 metric. Under both RCPs, the threshold set for increased cool season temperatures will be

128 reached by 2014 in the southern Red Sea, southern India, the province of Papua in

129 Indonesia, and in the Bahamas (Fig. 1b). In contrast, under RCP8.5, increased cool

130 season temperatures were not projected to occur until the 2030s and 2040s for much of

131 the Coral Triangle, Madagascar and Hawaii, and not until the 2050s and 2060s for

132 locations throughout the far south Pacific, such as French Polynesia (Fig. 1b). The

133 projected years for these locations were all roughly a decade later under RCP4.5 (Fig.

134 1b). The median years for the projections were 2036 (RCP8.5) and 2043 (RCP4.5).

135 Under RCP8.5, the threshold set for increased cool season temperatures is reached at

$13620 \%$ of reef locations by 2020 and for $17 \%$ after 2050 (remaining $63 \%$ fall between

137 2020-2050) (Fig. 2e).

139 Spatial patterns for projections of the pathogen virulence metric (i.e., for Vibrio

140 corallilyticus, when the number of months that temperatures are $\geq$ the MMM is double

141 that observed on average from 2006-2011) were similar to those found for the host

142 susceptibility metric. Reefs in the tropics will experience this condition earlier than sub-

143 tropical reefs (Fig. 1c), with little variation between the two RCPs. The Caribbean was an 
144 exception to this latitudinal pattern; the years that sub-tropical reefs in the Caribbean

145 were projected to experience a doubling of months at or above MMM (i.e., 2020) were

146 among the earliest projected under both RCPs. For sub-tropical reefs in the south Pacific

147 and Red Sea, the target stress level will be reached 20 or more years later, in the mid

148 2040s. The median years for this projection were 2031 (RCP8.5) and 2030 (RCP4.5), 20

149 years later than the median for the host susceptibility metric.

151 For most reef locations ( $\sim 80 \%$ for both RCPs), the models projected timing of increased

152 host-susceptibility to occur earliest (Fig. 1a) and for increased pathogen virulence (for

153 Vibrio corallilyticus) to occur latest (Fig. 1c). Under RCP8.5 at least one of the three

154 types of temperature conditions favouring disease development were projected to be

155 surpassed at all reef locations by 2031, and $80 \%$ of reefs will have experienced one of the 156 conditions by 2020 (Fig. 3a,b; S1a,b).

158 There was limited variation between the two RCPs in the projected year that the three

159 conditions favouring disease development would be reached (Fig. 3b and Fig. S1b).

160 Across all reef locations, the average difference in projections between RCP8.5 and

161 RCP4.5 was less than 1 year for the host susceptibility and pathogen virulence thresholds.

162 For the pathogen abundance metric, the average difference between the two RCPs was $\sim 6$

163 years. This difference is likely inconsequential given the standard deviation of model

164 outputs is $\sim 6$ years for both scenarios (Fig. 2e,h). The minor nature of differences in the

165 projection outputs for the two RCPs reflects the slow divergence of RCP4.5 from RCP8.5

166 over the coming two decades ${ }^{22}$. Even drastic cuts to emissions outputs and emissions 
167 growth required to achieve the $\mathrm{CO}_{2}$ concentrations characteristic of RCP4.5 do not

168 prevent all of the disease conditions set here from being surpassed at $>75 \%$ of reef

169 locations by 2090 (Fig. 2 and Fig. S1b).

170

\section{Comparing coral disease and bleaching}

172 The same model ensemble for RCP8.5 was used to project the onset of annual severe

173 bleaching conditions, defined as the year in which 8 DHWs is exceeded annually during

174 the warm season ${ }^{23}$. Currently, most corals will bleach once 8 DHWs is reached (Fig. 3),

175 and coral diversity and cover are likely to decline dramatically when temperature stress

176 of this severity begins to recur with insufficient time for recovery ${ }^{23}$. We sought to

177 determine whether temperature conditions that favour disease development are projected

178 to occur earlier or later than annual severe coral bleaching. To make this comparison, we

179 calculated the difference in the number of years between the projected timing of any two

180 of the three temperature conditions set here for coral disease and the onset of annual

181 severe bleaching conditions (Fig. 3d). Under RCP8.5, at least two of the three disease-

182 favouring temperature conditions occurred at $96 \%$ of reef locations (Fig. 3d) before the

183 onset of annual severe bleaching (98\% under RCP4.5, Fig. S1d). All three conditions

184 occur before the onset of annual severe bleaching at $40 \%$ of locations. The comparisons

185 of projected timing of disease versus bleaching conditions offered here suggest disease

186 outbreaks will be at least as great a driver of future coral reef condition and community

187 composition as bleaching.

189 Anthropogenic stress patterns and disease risk 
190 Anthropogenic stress is likely to be as important a driver of coral disease dynamics over

191 the coming decades as the temperature conditions presented here ${ }^{24-27}$. The Integrated

192 Local Threat (ILT) Index ${ }^{28}$ combines four threats that increase disease susceptibility:

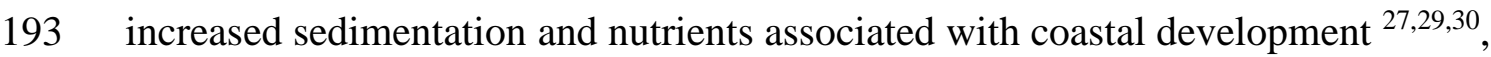

194 watershed-based pollution ${ }^{26,29-32}$, marine-based pollution and damage ${ }^{25,33,34}$, and injuries

195 associated with fishing activities, particularly destructive fishing ${ }^{12}$. The ILT index (500-

196 m resolution) results are resampled here to match the climate model grid used for the

197 temperature projections and the highest threat level within each model pixel is displayed

198 (Fig. 4a). This ensures the global patterns can be seen at the resolution the figure is

199 printed within the article.

201 Anthropogenic stress and climate stress are combined here in a disease risk summary, as

202 both are likely to drive future patterns in disease outbreak likelihood. Ecosystem impacts

203 from coral disease have the potential to be equal to or exceed those of severe bleaching

204 stress when two (or all three) of the disease-favouring conditions occur before the onset

205 of annual severe bleaching. Outbreak likelihood is also higher when anthropogenic stress

206 is either high or very high. This logic was applied to produce 5 criteria for relative

207 outbreak likelihood over the coming 20-30 years, which we describe as 'disease risk'

208 (Fig. 4b). Locations with greater relative risk (\#'s 2-5 in Fig. 4b; 22\% of locations) were

209 southern Florida, the southern and eastern Caribbean, Brazil, the province of Papua in

210 Indonesia, Philippines, Japan, India, northern Maldives, the Persian Gulf and the Red Sea

211 (Fig. 4b). For the combined disease risk metric, relative risk was considered lower for

212 locations where anthropogenic stress was low or medium, a condition found for $78 \%$ (see 
213 Fig. 4 caption) of reef locations. Some of these locations included Hawaii, the central and

214 south Pacific, Australia, Thailand and Madagascar (Fig. 4b). The disease risk summary

215 can be seen at the resolution of the anthropogenic stress data $(500 \mathrm{~m})$ in a high-resolution

216 image presented in the electronic supplementary material (see Fig. S2). The high-

217 resolution image complements Fig. 4 enabling viewers to zoom into reef locations to

218 interpret disease risk in relation to the actual rather than resampled anthropogenic stress

219 data. The disease risk summary reflects that anthropogenic stress is only high or very

220 high at $22 \%$ of locations. However, at almost all reef locations (>95\%), 2 of the 3

221 temperature conditions conducive to disease development occurred before the onset of

222 annual severe bleaching. The risk of coral diseases due to climate change (ignoring

223 anthropogenic stress) is high at nearly all reef locations.

225 Future applications and conclusions

226 These are the first climate-model-based projections of conditions that influence the

227 likelihood of marine disease outbreaks. Some important complexities are necessarily

228 excluded here so that global-scale conservative projections could be produced. The main

229 examples are: 1) variation among and within coral communities and species in host

230 susceptibility due to variation in genetics related to immunity, the expression of

231 immunity genes, and exposure to environmental disturbances and anthropogenic stress, 2)

232 the potential for coral evolution of resistance, which will be highly variable among and

233 even potentially variable within species, 3) the relationships between temperature

234 conditions and the virulence of other pathogens that cause diseases in stony corals, which

235 are not as well known or understood as Vibrio coralliilyticus and white syndromes, and 
236 4) extreme stochastic events such as extreme climatic events or the evolution of new

237 'super' pathogens, which could invalidate some of the presented conclusions. Other

238 possible conditions that can increase disease susceptibility and pathogen abundance and

239 virulence that are not included here are: sediment runoff and lowered salinity following

240 monsoonal rain events, and coral injuries from cyclones ${ }^{35,36}$ or predation by coral-

241 feeding gastropods ${ }^{37}$, crown-of-thorns starfish ${ }^{38}$, and reef fish ${ }^{39,40}$. Future scenarios that

242 include ocean acidification projections would also be valuable for understanding

243 conditions that increase coral disease susceptibility and pathogen virulence. Members of

244 the research community can use the data presented here to refine or produce higher-

245 resolution projections for areas for which spatially explicit data on some or all of the

246 information described above becomes available.

248 The standard caveats and assumptions related to the use of climate models also apply

24941,42 , and two are especially pertinent. Firstly, model resolution is coarse and a $1 \times 1^{\circ}$ cell

250 can contain many individual coral reefs, a fact related to the computational-intensiveness

251 of climate modeling and to modeling uncertainties (see below). While spatial variation

252 within single model cells is not resolved here, there is considerable variation within reef

253 regions in the projected timing of all three temperature conditions for disease and in

254 anthropogenic stress. Therefore, even at this resolution, the results can be used to target

255 applied research and management actions. Secondly, all climate models have

256 uncertainties and vary greatly in their capacity to project trends in key drivers of climate

257 in the tropics, such as the El Niño Southern Oscillation and its global teleconnections. We

258 include the standard deviation around the ensemble average (the 'model spread') for each 
259 temperature condition (Fig. 2d-i). The spread in the model results is small (standard

260 deviation of 2-6.5 years), which increases confidence in the major conclusions presented

261 based on the ensemble results and supports use of the ensemble rather than one or more

262 of the individual models. A review of the robustness and uncertainties in the new CMIP5

263 climate model projections (used here) suggests that climate models are improving,

264 representing more climate processes in greater detail, and that the "uncertainties should

265 not stop decisions being made" ${ }^{41}$. For this study, the relevant decisions involve the

266 targeting of actions to reduce anthropogenic stress and trials of the efficacy of

267 interventions that reduce disease impacts and support recovery.

269 Currently, the role of disease as a significant driver of future reef community composition

270 is under-appreciated, especially in the Indo-Pacific, and needs to be given greater

271 consideration for at least two reasons. Disease has a tendency to result in greater coral

272 mortality than bleaching ${ }^{14,43,44}$. Secondly, given the strong links between anthropogenic

273 stress and disease susceptibility ${ }^{24,26,29,30}$, management actions that reduce anthropogenic

274 stress are probably more likely to reduce the prevalence and severity of coral diseases

275 than reduce the impacts of thermal bleaching. Immediate actions to reduce anthropogenic

276 stress are needed at locations with high or very high anthropogenic stress (Fig. 4a), and

277 are especially urgent at locations also predicted to experience all three temperature

278 conditions set here in the coming two decades (Fig. 4b). These sets of conditions apply to

$279 \sim 20 \%$ of the reef locations (Fig. 4b, categories 4 and 5). These locations are priority

280 targets for proactive conservation efforts to reduce anthropogenic stress, such as

281 managing watersheds and coastal development, reducing destructive fishing, and 
282 addressing other extractive practices. Furthermore, there is a need for collaborative

283 efforts between researchers and managers to both better understand disease outbreaks and

284 test reactive management interventions that reduce disease transmission rates. Examples

285 include quarantining or culling infected corals, which could be followed by actions that

286 mitigate impacts and support recovery such as managing human activities through

287 temporary closures or other use restrictions. Many of these actions (reviewed in ${ }^{45,46}$ ) are

288 currently experimental and only feasible at small local scales. Trials of the efficacy of

289 these actions can lead to broader implementation in the coming decades.

291 There is also a need for researchers and managers to expand upon the currently very

292 limited suite of tools that forecast conditions conducive to coral disease outbreaks ${ }^{20,47}$.

293 New early warning systems will need to be built into coral disease response plans. Such

294 plans can help managers consider and justify various decisions and investments in both

295 targeted monitoring and trials/implementation of actions to reduce disease impacts and

296 support recovery. A coral disease response plan framework has been developed for the

297 Great Barrier Reef in Australia ${ }^{39}$ and for Hawaii but coral disease response plans have

298 not been as widely adopted as coral bleaching response plans ${ }^{46}$.

300 Perhaps more than any findings to date, the results presented herein indicate that

301 increases in the prevalence and severity of coral diseases will be a major future driver of

302 decline and changes in coral reef community composition, and at least as great a driver as

303 coral bleaching. Elevated temperatures that increase host susceptibility, pathogen

304 abundance or virulence are either already occurring or are projected to occur in the

305 coming decades at almost all reef locations. This is true irrespective of whether nations 
306 are able to sufficiently cut emissions such that RCP4.5 better characterizes our emissions

307 trajectory than RCP8.5. There is great spatial variation in the projected timing of the

308 disease-favouring conditions, which is in keeping with much new research highlighting

309 that the impacts of climate change will not be spatially uniform. The spatial variation in

310 the projections we present also emphasises the value for decision-making of developing

311 near real-time early warning systems and seasonal outlooks for marine diseases.

\section{Methods}

315 Climate model data: Monthly sea surface temperature (SST) data were retrieved for

316 each available GCM from the World Climate Research Programme's CMIP5 data set

317 (from http://www.esg.llnl.gov) for RCP8.5 $(n=33)$ and RCP4.5 (n=35, see Table S1 for

318 list of models). Methods for matching the start of each model with the observed

319 climatology used (1982-2005), correcting model means, replacing annual cycles, and

320 interpolation routines are all as per ${ }^{48}$. Projections produced are based on model runs that

321 are then averaged, rather than on ensemble means ${ }^{23,48}$, ensuring variance among models

322 is examined and presented for each projection output (Fig. 2d-i).

\section{Temperature conditions that increase disease susceptibility and/or pathogen}

325 virulence: Three temperature conditions are examined that increase the susceptibility of

326 coral hosts to disease or increase pathogen abundance or virulence.

327 For all of the projected conditions, results are shown for reef locations only (also as per

$\left.328{ }^{48}\right)$ rasterised to match the climate model grid ( $\mathrm{n}=1748$ pixels or 'reef locations').

329 Histograms and plots of the spread in results (average \pm 1 stdev) from the climate models 
330 are presented for each temperature condition with percentages based on the total number

331 of reef locations.

333 (1) Host susceptibility: Field studies from all reef regions have shown that coral

334 diseases often follow sub-lethal bleaching, presumably when energy and

335 resources required for the maintenance of disease resistance are reduced ${ }^{14,16,49-51}$.

336 For sensitive species globally, thermal stress represented by 4 Degree Heating

337 Weeks (DHWs) is a conservative threshold for predicting the presence of sub-

338 lethal bleaching, since the global optimum predictor of bleaching is slightly

339 higher at $\sim 6$ DHWs ${ }^{52}$. Here, our 'host susceptibility' metric identifies when a

340 decade starts in which thermal stress is projected to exceed 4 DHWs at least 3

341 times. This frequency was selected because the return period is so short ( 3 years)

342 that corals will likely struggle to recover between bleaching events thus remaining

343 in a weakened and therefore susceptible state.

344 (2) Pathogen abundance: Research on diseases affecting agricultural crops indicates

345 that survival rates of both causative agents and disease vectors increase during

346 anomalously warm winters (called 'overwintering' ${ }^{6}$ ). While many long-term

347 studies of coral diseases detect higher levels of disease prevalence when

348 temperatures peak ${ }^{12}$, a common group of coral diseases, white plague and white

349 syndromes, have been found in higher abundances during warm summers that

350 follow mild winters (neither excessively cool or warm ${ }^{20}$ ). This is likely due to a

351 combination of overwintering and increased host susceptibility because warmer

352 winters provide less of a reprieve for corals between warm seasons. Here, the 
'pathogen abundance' metric indicates the first year in which the means of the three months centered on the coolest month are $\geq 0.5^{\circ} \mathrm{C}$ above the minimum monthly mean (coolest month) calculated from a 1982-2008 climatology. This roughly equates to the thermal stress associated with mild winters in ${ }^{20}$ of 2-6.5 ${ }^{\circ} \mathrm{C}$-weeks, which are calculated from a higher baseline than is used here and which resulted in an increased abundance of white syndromes in Australia during the following summers.

(3) Pathogen virulence: The model coral pathogen used here, Vibrio coralliilyticus, is the causative agent of a number of virulent white syndromes on Indo-Pacific corals, causing progressive tissue loss and ultimately, whole colony mortality. We reviewed experimental studies and related the temperatures at which the virulence and host-seeking motility behaviors (i.e., chemotaxis and chemokinesis) of this pathogen are augmented to the maximum monthly mean (MMM, warmest month) at each sampling location (see Table S2). For each of three strains of $V$. coralliilyticus, the pathogen becomes virulent within $2.5^{\circ} \mathrm{C}$ of the MMM calculated for the period 1982-2008 at the respective sampling location, so we conservatively set the threshold as MMM (1982-2008). Here, the metric 'pathogen virulence' identifies when the number of months in which temperatures exceed the MMM becomes twice that observed, on average, during 2006-2011. This represents the timing of anticipated increases in virulence and in the projected number of months corals are exposed to the virulent pathogen.

375 Maps and histograms (standardised to the total number of reef locations) are presented 376 for: a) the earliest year by which at least one disease condition will be met, b) the year by 
377 which all three disease conditions will be met, (c) the year from which annual severe

378 bleaching stress is projected, and (d) the difference between the year by which at least

379 two of the three disease conditions are met and the onset of annual severe bleaching (8

380 DHWs).

382 A map is also presented of anthropogenic stress using the Integrated Local Threat (ILT)

383 index developed for Reefs at Risk Revisited ${ }^{28}$, as is described in the paper. We resample

384 these data to our climate model grid by taking the highest level of stress within each

385 model pixel to produce a visual summary interpretable at article-resolution. The disease

386 risk summary presented for RCP8.5 grades risk based on 5 criteria: 1) none of the

387 following criteria apply; 2) two of three climate stressors occur before the onset of annual

388 severe bleaching and anthropogenic stress is high; 3) as for criterion 2 but anthropogenic

389 stress is very high; 4) all three climate stressors occur before the onset of annual severe

390 bleaching and anthropogenic stress is high; and 5) as for criterion 4 but anthropogenic

391 stress is very high. A 500-m resolution image of the disease risk summary is provided as

392 electronic supplementary material enabling readers to zoom into reefs of interest to see

393 which reefs meet the criteria set. The percentage values cited in the paper for reef pixels

394 that meet each of the five criteria are derived at 500-m resolution rather than from the

395 resampled data. 


\section{References}

1. National Climatic Data Center. Global Analysis - August $2014 \mid$ State of the Climate. ncdc.noaa.gov at <http://www.ncdc.noaa.gov/sotc/global/2014/8>

2. Slezak, M. Oceans get into hot water. New Scientist 224, 8-9 (2014).

3. Hewson, I. et al. Densovirus associated with sea-star wasting disease and mass mortality. Proc Natl Acad Sci 111, 17278-17283 (2014).

4. Groner, M. L. et al. Host demography influences the prevalence and severity of eelgrass wasting disease. Dis. Aquat. Org. 108, 165-175 (2014).

5. Savary, S., Nelson, A., Sparks, A. H. \& Willocquet, L. International agricultural research tackling the effects of global and climate changes on plant diseases in the developing world. Plant Disease 95, 1204-1216 (2011).

6. Garrett, K. A., Dendy, S. P. \& Frank, E. E. Climate change effects on plant disease: genomes to ecosystems. Annu Rev Phytopathol 44, 489-509 (2006).

7. Altizer, S., Ostfeld, R. S., Johnson, P. T. J., Kutz, S. \& Harvell, C. D. Climate change and infectious diseases: from evidence to a predictive framework. Science 341, 514-519 (2013).

8. Rogers, D. J. \& Randolph, S. E. The Global Spread of Malaria in a Future, Warmer World. Science 289, 1763-1766 (2000).

9. van Lieshout, M., Kovats, R. S., Livermore, M. T. J. \& Martens, P. Climate change and malaria: analysis of the SRES climate and socio-economic scenarios. Global Environ Change 14, 87-99 (2004).

10. Béguin, A. et al. The opposing effects of climate change and socio-economic development on the global distribution of malaria. Global Environ Change 21, 1209-1214 (2011).

11. Ruiz-Moreno, D., Vargas, I. S., Olson, K. E. \& Harrington, L. C. Modeling Dynamic Introduction of Chikungunya Virus in the United States. PLoS Negl Trop Dis 6, e1918 (2012).

12. Burge, C. A. et al. Climate change influences on marine infectious diseases: implications for management and society. Аnпи Rev Marine Sci 6, 249-277 (2014).

13. Bruno, J. F., Selig, E. R., Casey, K. S., Page, C. A. \& Willis, B. L. Thermal stress and coral cover as drivers of coral disease outbreaks. PLoS Biol 5, e124 (2007).

14. Miller, J. et al. Coral disease following massive bleaching in 2005 causes $60 \%$ decline in coral cover on reefs in the US Virgin Islands. Coral Reefs 28, 925-937 (2009).

15. Harvell, D., Altizer, S., Cattadori, I. M., Harrington, L. \& Weil, E. Climate change and wildlife diseases: when does the host matter the most? Ecology (2009). doi:10.1890/08-0616.1

16. Harvell, D., Jordán-Dahlgren, E. \& Merkel, S. Coral disease, environmental drivers, and the balance between coral and microbial associates. Oceanography 20, 172-195 (2007).

17. Sato, Y., Bourne, D. G. \& Willis, B. L. Dynamics of seasonal outbreaks of black band disease in an assemblage of Montipora species at Pelorus Island (Great Barrier Reef, Australia). Proc Biol Sci 276, 2795-2803 (2009).

18. Riegl, B. Effects of the 1996 and 1998 positive sea-surface temperature anomalies 
444

445

446

447

448

449

450

451

452

453

454

455

456

457

458

459

460

461

462

463

464

465

466

467

468

469

470

471

472

473

474

475

476

477

478

479

480

481

482

483

484

485

486

487

488

on corals, coral diseases and fish in the Arabian Gulf (Dubai, UAE). Mar Biol 140, 29-40 (2002).

19. Cervino, J. M. et al. Relationship of Vibrio species infection and elevated temperatures to yellow blotch/band disease in Caribbean corals. App Environ Microbiol 70, 6855-6864 (2004).

20. Heron, S. F. et al. Summer Hot Snaps and Winter Conditions: Modelling White Syndrome Outbreaks on Great Barrier Reef Corals. PLoS ONE 5, e12210 (2010).

21. Maynard, J. A. et al. Predicting outbreaks of a climate-driven coral disease in the Great Barrier Reef. Coral Reefs 1-11 (2010). doi:10.1007/s00338-010-0708-0

22. van Vuuren, D. P. et al. The representative concentration pathways: an overview. Climatic Change 109, 5-31 (2011).

23. van Hooidonk, R. J., Maynard, J. A., Manzello, D. \& Planes, S. Opposite latitudinal gradients in projected ocean acidification and bleaching impacts on coral reefs. Glob Change Biol 20, 103-112 (2014).

24. Aeby, G. S. et al. Patterns of Coral Disease across the Hawaiian Archipelago: Relating Disease to Environment. PLoS ONE 6, e20370 (2011).

25. Lamb, J. B. \& Willis, B. L. Using Coral Disease Prevalence to Assess the Effects of Concentrating Tourism Activities on Offshore Reefs in a Tropical Marine Park. Conservation Biology 25, 1044-1052 (2011).

26. Vega Thurber, R. L. et al. Chronic nutrient enrichment increases prevalence and severity of coral disease and bleaching. Glob Change Biol 20, 544-554 (2013).

27. Pollock, F. J. et al. Sediment and Turbidity Associated with Offshore Dredging Increase Coral Disease Prevalence on Nearby Reefs. PLOS ONE 9, e102498 (2014).

28. Burke, L. M., Reytar, K., Spalding, M. \& Perry, A. Reefs at risk revisited. (World Resources Institute, 2011).

29. Kline, D. I., Kuntz, N. M. \& Breitbart, M. Role of elevated organic carbon levels and microbial activity in coral mortality. Marine Ecology (2006).

30. Bruno, J. F., Petes, L. E., Drew Harvell, C. \& Hettinger, A. Nutrient enrichment can increase the severity of coral diseases. Ecol Letters 6, 1056-1061 (2003).

31. Haapkylä, J. et al. Seasonal Rainfall and Runoff Promote Coral Disease on an Inshore Reef. PLOS ONE 6, e16893 (2011).

32. Sutherland, K. P., Shaban, S., Joyner, J. L., Porter, J.W., \& Lipp, E.K. Human Pathogen Shown to Cause Disease in the Threatened Eklhorn Coral Acropora palmata. PLoS ONE 6(8): e23468. doi:10.1371/journal.pone.0023468 (2011).

33. Lamb, J. B., True, J. D., Piromvaragorn, S. \& Willis, B. L. Scuba diving damage and intensity of tourist activities increases coral disease prevalence. Biological Conservation (2014). doi:10.1016/j.biocon.2014.06.027

34. Hawkins, J. P. et al. Effects of recreational scuba diving on Caribbean coral and fish communities. Conservation Biology 13, 888-897 (1999).

35. Miller, M. W., \& Williams, D. E. Coral disease outbreak at Navassa, a remote Caribbean island. Coral Reefs, 26, 97-101 (2007).

36. Bruckner, A. W., \& Bruckner, R. J. Outbreak of coral disease in Puerto Rico. Coral Reefs, 16, 260-260 (1997). 
37. Nicolet, K., M. Hoogenboom, N. Gardiner, M. Pratchett, and B. Willis. The corallivorous invertebrate Drupella aids in transmission of brown band disease on the Great Barrier Reef. Coral Reefs 32:585-595 (2013).

38. Katz, S. M., Pollock, F. J., Bourne, D. G., \& Willis, B. L. (2014). Crown-ofthorns starfish predation and physical injuries promote brown band disease on corals. Coral Reefs, 33, 705-716 (2014).

39. Aeby, G. S., \& Santavy, D. L. (2006). Factors affecting susceptibility of the coral Montastraea faveolata to black-band disease. Marine Ecology Progress

Series,318, 103-110.

40. Casey, J. M., T. D. Ainsworth, J. H. Choat, and S. R. Connolly. Farming behaviour of reef fishes increases the prevalence of coral disease associated microbes and black band disease. Proceedings of the Royal Society B: Biological Sciences 281: 20141032 (2014).

41. Knutti, R. \& Sedláček, J. Robustness and uncertainties in the new CMIP5 climate model projections. Nature Clim Change - (2012). doi:10.1038/nclimate1716

42. van Hooidonk, R. \& Huber, M. Effects of modeled tropical sea surface temperature variability on coral reef bleaching predictions. Coral Reefs 31, 121131 (2012).

43. Cróquer, A. \& Weil, E. Changes in Caribbean coral disease prevalence after the 2005 bleaching event. Dis Aquat Org 87, 33-43 (2009).

44. Aeby, G. S., Ross, M., Williams, G. J., Lewis, T. D. \& Work, T. M. Disease dynamics of Montipora white syndrome within Kaneohe Bay, Oahu, Hawaii: distribution, seasonality, virulence, and transmissibility. Dis Aquat $\operatorname{Org}$ 91, 1-8 (2010).

45. Beeden, R., Maynard, J. A., Marshall, P. A., Heron, S. F. \& Willis, B. L. A Framework for Responding to Coral Disease Outbreaks that Facilitates Adaptive Management. Environmental Management 49, 1-13 (2012).

46. Maynard, J. A. et al. A Strategic Framework for Responding to Coral Bleaching Events in a Changing Climate. Environmental Management 44, 1-11 (2009).

47. Maynard, J. A., Anthony, K., Harvell, C. D. \& Burgman, M. A. Predicting outbreaks of a climate-driven coral disease in the Great Barrier Reef. Coral Reefs (2011). doi:10.1007/s00338-010-0708-0

48. van Hooidonk, R., Maynard, J. A. \& Planes, S. Temporary refugia for coral reefs in a warming world. Nature Clim Change 3, 1-4 (2013).

49. Miller, J., Waara, R., Muller, E. \& Rogers, C. Coral bleaching and disease combine to cause extensive mortality on reefs in US Virgin Islands. Coral Reefs 25, 418 (2006).

50. Brandt, M. \& McManus, J. Disease incidence is related to bleaching extent in reefbuilding corals. Ecology 90, 2859-2867 (2009).

51. Muller, E. M., Rogers, C. S., Spitzack, A. S. \& Van Woesik, R. Bleaching increases likelihood of disease on Acropora palmata (Lamarck) in Hawksnest Bay, St John, US Virgin Islands. Coral Reefs 27, 191-195 (2008).

52. van Hooidonk, R. \& Huber, M. Quantifying the quality of coral bleaching predictions. Coral Reefs 28, 579-587 (2009). 
536 Correspondence and requests for materials should be sent to J Maynard via email at:

537 maynardmarine@gmail.com

\section{Acknowledgements}

539 This study was primarily funded by a grant from the National Oceanic and Atmospheric

540 Administration (NOAA) Climate Program Office prepared by SFH and awarded to CDH

541 and CME (NA13OAR4310127). Support was also provided by a National Science

542 Foundation Research Coordination Network grant to $\mathrm{CDH}$, in-kind support from NOAA

543 Atlantic and Oceanographic Meteorological Laboratory, as well as grants from the

544 NOAA Coral Reef Conservation Program, the US National Fish and Wildlife

545 Foundation, the Pacific Islands Climate Change Cooperative, the European Research

546 Commission, and The Nature Conservancy. Use of data from ${ }^{28}$ benefited from

547 discussions with L. Burke and K. Reytar. Figures were collaboratively developed with D.

548 Tracey. The contents in this manuscript are solely the opinions of the authors and do not

549 constitute a statement of policy, decision or position on behalf of NOAA or the U.S.

550 Government.

551

552 Author contributions

$553 \mathrm{JM}, \mathrm{CDH}, \mathrm{CME}, \mathrm{SFH}, \mathrm{RvH}, \mathrm{BW}, \mathrm{MG}, \mathrm{JL}$ and GW designed the study. RvH compiled

554 and analysed the climate model data in collaboration with JM. MP conducted the spatial

555 analysis required to build the maps upon which Figs. 3 and 4 and Figs. S1 and S2 are

556 based in collaboration with JM. JM, CDH, CME and BW wrote the manuscript with

557 assistance from all other authors.

\section{Competing financial interests statement}

559 The authors declare no competing financial interests.

\section{Supplementary Information}

561 Supplementary Information is linked to the online version of the paper at

562 www.nature.com/nature and includes a table listing the climate models used, a review of 
563 experimental studies that examined the effects of temperature on Vibrio coralliilyticus, a

564 panel figure for RCP4.5 that matches Fig. 3 here, and a 500-m resolution disease risk

565 summary figure that complements Fig. 4 here.

566 
568 Figure 1. Projections of temperature conditions that increase host susceptibility (a), pathogen abundance (b), and pathogen virulence (c) under RCPs 8.5 and 4.5. The conditions and condition thresholds are: (a) Host susceptibility - year in which thermal stress first exceeds 4 DHWs 3x per decade; (b) Pathogen abundance - first year in which the 3 cool season months exceed $0.5{ }^{\circ} \mathrm{C}$ above the minimum monthly mean (1982-2008); (c) Pathogen virulence - year in which the number of months of temperatures $\geq \max$ monthly mean (1982-2008) is twice that observed on average from 2006-2011. See Table S1 for a list of climate models.

\section{Figure 2. Histograms and model means and spreads for the projections of} temperature conditions under RCPs 8.5 and 4.5. For the histograms (top row), bins are 5 -year intervals and $n=1748$ reef locations. For model means and spreads ( 2 bottom rows), means are shown as the bold line and spreads are the mean \pm 1 stdev (grey shade). These data correspond to the model projections shown as maps in Fig. 1. See Table S1 for a list of climate models.

\section{Figure 3. Summaries of projections for disease and bleaching conditions under} RCP8.5. The earliest year (a) is the first year in which at least one of the three temperature conditions for disease shown in Fig. 1 will be reached. The year in which all three temperature conditions will be reached is shown in (b). The onset of annual severe bleaching is shown in (c), defined as temperature stress annually exceeding 8 DHWs $\left(\right.$ from ${ }^{23}$ ). The difference in timing between when at least 2 of the 3 temperature conditions for disease shown in Fig. 1 will be reached and (c) is shown in (d). Negative values in (d) mean at least 2 of the 3 temperature conditions for disease are projected to occur before annual severe bleaching conditions ( $96 \%$ of reef locations).

\section{Figure 4. Anthropogenic stress patterns and disease risk based on exposure to} anthropogenic and climate stress. Anthropogenic stress (a) is a resampling of the Reefs at Risk Revisited ${ }^{28}$ Integrated Local Threat index to the climate model grid used in Figs. 1 and 3; the highest value for stress within each model pixel is retained so that approximate global patterns can be interpreted at this resolution. Disease risk (b), in relative terms, relates to whether: 2 or 3 of the temperature conditions (from Fig. 1) occur before annual severe bleaching (ASB) (see Fig. 3c), and anthropogenic stress is high or very high. Reef location (model cell) counts and percentages are as follows and are from the 500-m resolution data, which are presented within Fig. S2: 1 (353485, 78\%), 2

604 